GU J Sci, Part C, 5(3): 127-137 (2017)

Gazi Üniversitesi
Fen Bilimleri Dergisi
PART C: TASARIM VE TEKNOLOJI
dergipark.gov.tr/http-gujsc-gazi-edu-tr

\title{
Türkiye İçin Yeni Nesil Acil Çağrı Sistemi
}

\author{
Ahmet APAK ${ }^{1, *}$, İlker ÜSTOĞLU \\ ${ }^{I}$ Ylldız Teknik Üniversitesi, Mühendislik Fakültesi, Kontrol ve Otomasyon Bölümü, 34220, Esenler/Istanbul
}

\begin{tabular}{|c|c|}
\hline & Öz \\
\hline Makale Bilgisi & $\begin{array}{l}\text { Avrupa Parlamentosu tarafindan kabul edilen 2015/758 sayılı yasa tasarıs1 ile acil çağr1 } \\
\text { ünitelerinin araçlarda kullanımı } 2018 \text { y1lı itibari ile zorunlu hale gelecek ve bu üniteler } 2018\end{array}$ \\
\hline $\begin{array}{l}\text { Başvuru: 05/10/2016 } \\
\text { Düzeltme: } 19 / 081 / 2017 \\
\text { Kabul: } 14 / 09 / 2017\end{array}$ & $\begin{array}{l}\text { Acil Çağrı Birliği } 2 \text { seviyeli çă̆ı merkezi modeline sahip bir ülke olarak mevcut trafik ve } \\
\text { yol yönetim sistemleri ve araç ve trafik acil yardım alt yapılarını yeni nesil modele uyarlamak } \\
\text { zorundadır. Bu çalışmada yeni nesil akıllı araç sistemlerinin yapılanması konusu tanıtılmakta } \\
\text { ve Türkiye için en uygun model gerek maliyet gerekse altyapısal olarak ilk kez ele } \\
\text { alınmaktadır. }\end{array}$ \\
\hline
\end{tabular}

\section{Anahtar Kelimeler}

Acil Yardim Sistemi

112 Servisi

Kurtarma Servisleri

Kaza Uyarl Sistemi

Acil Çă̆rı Unitesi

\section{Keywords}

Emergency Call System

112 PSAP

Rescue Services

Emergency Response Organizer

Emergency Call Unit

\section{Next Generation Emergency Call System For Turkey}

\section{GİRIŞ̧ (INTRODUCTION)}

Uluslar arası kaza ve yol veritabanı (IRTAD) üyesi ülkelerin 2015 yılında yayınlanan 2013 verilerini içeren raporunda, IRTAD üyesi ülkelerde yüz bin kişilik bölge verilerinde, yol kazalarındaki ölüm oranları 3 ile 13 kişi arasında değişmektedir [1]. Türkiye'de ise bu oran daha yüksek bir değer almaktadır [2]. Ülkeler, özellikle ölümlü kazaları azaltmak adına çeşitli düzenlemeler yapmakta, uluslar arası standartlar oluşturmaktadırlar. Bu bağlamda, Avrupa Parlamentosunun 2015/758 sayılı yasası gereğince Avrupa'da 2018 yılı Mart ayında yürürlüğe girecek biçimde acil yardım servisleri yeniden yapılandırılmıştır [3]. Dolayısı ile bu tarihten itibaren Avrupa Birliği sınırları içerisinde acil yardım çağrı üniteli araçlar yol almaya başlayacaktır. Türkiye de bu tür araç kullanımlarını başlatarak, acil yardım altyapılarını güncelleyerek ya da mevcut sistemleri yeniden yapılandırarak bu yeni düzenlemeye 2018 yılını izleyen yakın bir tarihte uyum gösterecektir. Ayrıca, acil yardım servisleri bu güncelleme veya yeniden yapılandırılmaya göre ilave görevler ile donatılacak, dolayısıyla mevcut personelin eğitilmesi ya da yeni personel alımı gibi durumlar ortaya çıkacaktır. Avrupa Parlamentosunun 2015/758 sayılı yasası analiz edildiğinde Türkiye' de hali hazırda yapılandırılmakta olan tüm kurtarma birimlerinin 112 numarası altında birleştirilmesi ve acil yardım servislerinin tek çatı altında toplanması durumlarına bir de Kara Taşıtı Kazası Acil Çağrı Cevap Birimi eklenecektir. 
Avrupa Acil Çağrı Birliği'nde (EENA) hâlihazırda uygulanmakta olan 6 tane model mimari mevcuttur. Bu mimariler farklı ülkelerce alt yapılarına uygun olarak tercih edilmektedir. Avusturya, Fransa, Almanya, İtalya ve Norveç acil çağrıların kurtarma servislerinden biri tarafindan cevaplanması esasına dayanan mimariyi kullanmaktadır (Model-1). Model-2 ise birincil acil yardım çağrı cevap birimleri tarafından filtrelenen çağrıların ikincil acil yardım çağrı birimleri tarafından anons edilmesi prensibine dayanan bir modeldir ve Birleşik Krallık, İrlanda ve Hollanda'da tercih edilmektedir. Romanya, birincil acil yardım çağrı cevap birimleri tarafından alınan çağrıların, kurtarma servislerinin tümüne iletilip, ilgili kurtarma servislerinden anons edildiği Model-3'ü kullanmaktadır. Model-4 ise 2 seviyeli acil çağrı merkezi modeli olarak bilinmekte, Madrid ve Ostrava şehirlerinde, Belçika ve Türkiye'de kullanılmaktadır. Model-4 olarak gruplandırılan bu yapıya ait prensip şeması Şekil-1'de verilmiştir. Finlandiya'da kullanılan Model-5'te ise kurtarma servislerinden bağımsız acil çağrı birimli sistemler yer almaktadır. Model-6 ise aynı bölgede birbirine bağlı acil çağrı servisleri yapısını içermekte ve Çek Cumhuriyeti, Bulgaristan ve İsviçre'de kullanılmaktadır [4]. Türkiye'de Model-4 altyapı çalışmaları tamamlanmamış olup sadece Akdeniz bölgesinde Antalya gibi belli başlı bazı şehirlerde sistem tam olarak hizmet vermeye başlamış durumdadır [5].

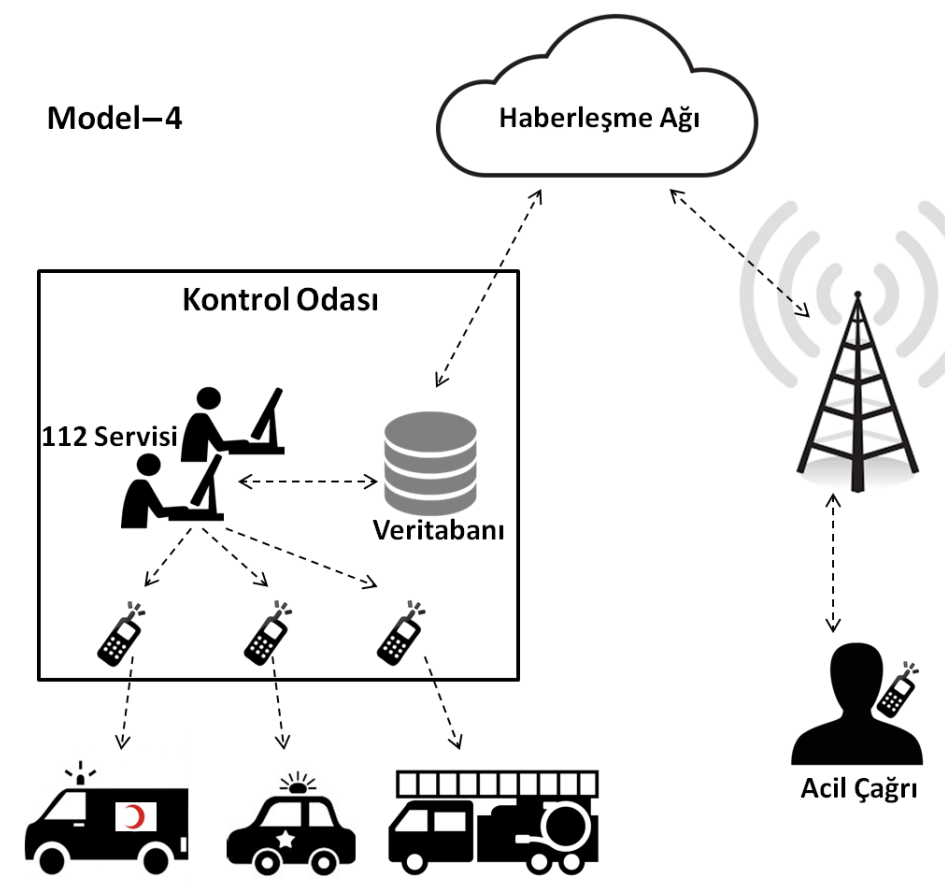

Şekil 1. 2 Seviyeli Acil Çă̆rı Merkezi Modeli

Model-4 sisteminde, acil yardım araması birey tarafından cep telefonu ve benzeri özel iletişim cihazları ile yapılır. Bu cihazlarda aramaya ilişkin mesaj, ses ve ilgili diğer veri tipleri işlenir ve mevcut haberleşme protokolleri aracılığıyla haberleşme kulesine, dolayısı ile bir haberleşme ağına iletilir [6]. Bu iletişimde haberleşme kulesinin kapasitesi, sinyalin gücü ve hangi kulenin verileri aldığına bağlı olarak acil çağn verileri depolanır, işlenir ve uygun protokollerde olmaları sağlanır. Acil çağrı bilgileri haberleşme ağı vasıtasıyla acil çağrı merkez binasında yer alan kontrol odasındaki acil çağrıları cevaplamakla görevli 112 servisine iletir. Bu tür bir servisin çalışanları az, orta veya çok eğitimli yapıda olabilirler. Türkiye'deki 112 servisine ait kontrol odası modelinde acil çağrıları cevaplama ve aynı merkezde yer alan ilgili kurtarma servislerine (ambulans, polis ve yangın kurtarma) çağrnya ait verileri aktarma görevini yürüten personelin orta seviye eğitime sahip olduğu kabul edilmektedir.

Kara taşıtı acil çağnı üniteleri Türkiye'de zorunlu hale geldikten sonra EENA 2 seviyeli çağrı merkezi modelinin Türkiye uygulamasında karşılaşacağımız alt sistemler; araçlardaki acil çağnı üniteleri, araç içi 
donanım ve yazılımları, 112 ve acil yardım servis birimlerini içeren kontrol odaları, otomatik ve/veya manüel acil çağrı cevap birimleri olarak Şekil-2'de de verildiği gibi gruplandırılabilir.

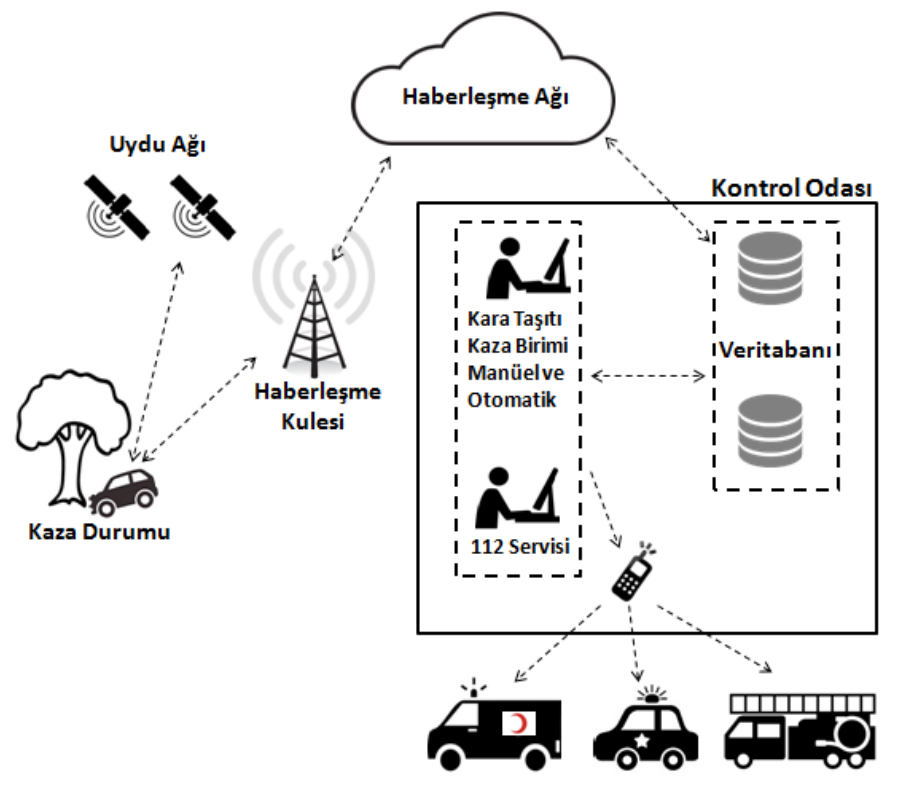

Şekil 2. EENA Model-4, Türkiye'deki Yeni Mimari

Model-4'ten uyarlanarak altyapı, mühendislik ve maliyet açısından birbirinden farklı çeşitlerde birçok alt mimari geliştirilebilir. Bunlar arasında öncelikle dikkat çeken 6 alt mimari şu biçimde oluşturulabilir: Çeşit-1 diyeceğimiz ilk alt mimaride kara taşıtı manüel ve otomatik kaza birimleri, 112 servisi ve anonsu yapan birim ile aynı ortamdadır (kontrol odası ya da bina). Çeşit-2'de ise anonsu yapan üç birim söz konusudur, bunlar polis, ambulans ve yangın ekipleri olarak ayrılır. Bir diğer alt mimaride kara taşıtı manüel ve otomatik kaza birimleri ayr birimler olarak var olup 112 servisi ve anonsu yapan tek bir birim ile aynı ortamdadır (Çeşit-3). Kara taşıtı manüel ve otomatik kaza birimleri ayrı birimler olarak aynı ortamda yer aldığı, 112 servisinin farklı bir ortamda bulunduğu ve anonsu yapan tek bir birim ile iletişime geçilen yapılanma ise Çeşit-4 olarak tanımlanabilir. Çeşit-4'deki anonsu yapan polis, ambulans ve yangın ekipleri olarak üç birim belirlenirse bu durumda ortaya çıkan alt mimari Çeşit-5 olarak verilebilir. Çeşit-6 da ise kara taşıtı manüel ve otomatik kaza birimleri aynı birimler olarak 112 servisi ile aynı ortamda olan ancak farklı bir binada yer alan anonsu yapan tek bir birim ile iletişime geçilen yapılanma olarak tanımlanabilir.

Yayında ikinci bölümde maliyet modeli konusu ele alınacak, maliyete etki eden faktörler ve parametreler tanıtılacaktır. Maliyet açısından Türkiye için en uygun mimarinin ne olması gerektiğine yine bu bölümde karar verilecektir. Yayının sonunda sonuçlar tartışılacak ve gelecekte yapılacak işler tanımlanacaktır.

\section{MALIYYT MODELI}

Bu bölümde kara taşıtı acil çağrı ünitelerinin araç içinde zorunlu hale gelmesiyle birlikte ortaya çıkan yeni mimariler için genel bir maliyet modeli ele alınacak ve bu incelemeler kâr maliyet oranı (KMO), net kâr (NK) ve toplam acil servis maliyetleri (TASM) değişkenleri değerlendirilerek ortaya konacaktır. 


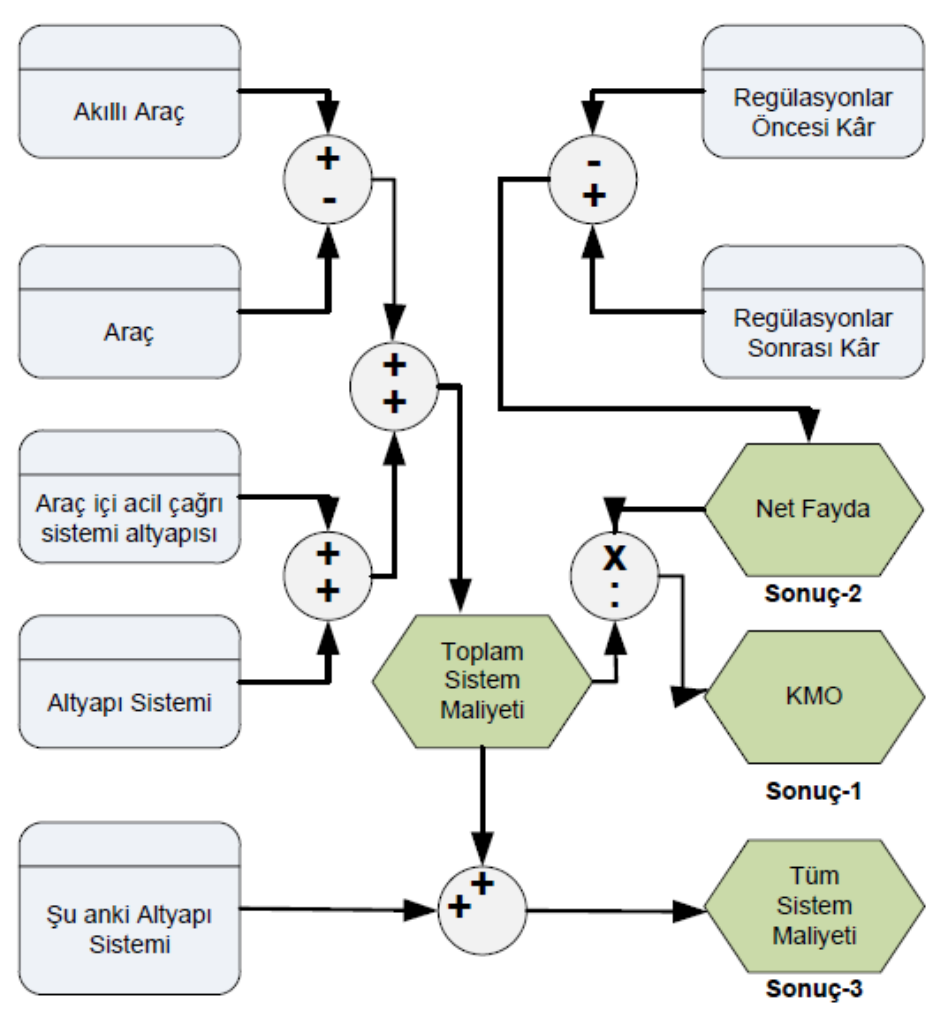

Şekil 3. Akallı Araç Sistemleri Maliyet Modeli Yapısı

Akıllı araç sistemleri maliyet modeli Şekil-3'de verilmiş olup kâr maliyet oranı en genel anlamda aşağıdaki formül ile ifade edilebilir.

$$
\mathrm{KMO}=\mathrm{f}(\mathrm{AAS}-\mathrm{NAS}) / \mathrm{g}(\mathrm{ASM}+\mathrm{KM})
$$

(2.1)'de belirtilen $\mathrm{f}($.$) dönüșümü araç sistemleri ve yol emniyeti ile ilgili bir fonksiyonu, g($.$) dönüșümü ise$ altyapı sistemleri ve araç içine eklenen acil yardım çağrı ünitesine ait bir fonksiyonu ifade etmektedir. KMO, akıllı araç sistemlerinin yıllık bazda toplam maliyetine (AAS), akıllı araç fonksiyonları olmayan normal bir araç sisteminin toplam maliyetine (NAS), altyap1 sistem maliyetlerine (ASM) ve araç içine eklenen yeni acil çağrı ünite maliyetine (KM) bağlı bir ifadedir. Tüm bu maliyetler Şekil-3'de toplam sistem maliyeti olarak ifade edilmiştir. Sistemin net kârı, (2.1)'deki f(AAS-NAS) olarak ifade edilirken, toplam maliyeti ise aşağıdaki gibi ifade edilir.

$$
\mathrm{TASM}=\mathrm{f}(\mathrm{KMO})+\mathrm{h}\left(\mathrm{ASM}^{\prime}\right)
$$

(2.2)'de TASM toplam acil servis maliyetlerini, $\mathrm{f}(\mathrm{KMO})$ kâr maliyet oranına ait maliyet fonksiyonu oluşturan (2.1)'deki maliyetleri, $\mathrm{h}($.$) şu anki var olan acil servis maliyetlerine ait bir fonksiyonu ve ASM'$ ise, şu anki sistemde var olan acil servis maliyetlerini ifade etmektedir. ASM' maliyeti (i) acil servis birimlerine ait alt yap1, (ii) ofis, (iii) haberleşme sistemi, (iv) yıllık vergi ve acil arama, (v) veri tabanı sistemi (vi) arama ve anons işlemlerini yapan personelin bilgisayar yazılım ve donanım maliyetlerini içermektedir. 


\subsection{Akıllı Araç Sistemleri ve Alt Yapı Maliyet Modelleri}

Araç sistemleri modeli (2.1)'de f(AAS-NAS) olarak tanımlanmış; kaza öncesi, kaza anı ve kaza sonrası araç teknolojilerini içeren araçların maliyet modelini ve akıllı araç teknolojileri olmayan normal bir aracın maliyet modelini ele alarak tüm yapının net kârını ortaya koymuştur. Net kâr, araçların akıllı araç teknolojileri ile yapılandırılması, altyapı ve komponent maliyetlerine karşı1ık, akı1lı araç teknolojilerinin uygulanması sonucu azalan kaza ve ölüm oranlarının getirdiği faydaya göre ifade edilmiştir. Şekil-4'te prensip şeması verilen sistem akıllı araç sistemleri maliyet modelinin alt bileşenleri ve model çıkışları aşağıda tanımlanmıştır:

Ekipman Oranı (Araç Akıllı Sistem Oranı): Avrupa Otomotiv Üreticileri Birliği (ACEA) tarafindan her yıl açıklanan bir orandır. Türkiye'nin de içinde bulunduğu Avrupa araç teknolojileri akıllı araç sistemi oranı 2015 yılında \%45'lerde iken 2020'lerde \%70'lere kadar çıkmaktadır [7]. Bu oran tümüyle otonom bir araç için \%100 kabul edilmektedir.

Araç Kilometresi: Yıllık taşınan yük ve yolcu kapasitesidir. Aracın binek araç, hafif ticari ya da ağır ticari araç olmasına göre değişen bir orandır. Karayolu kaza istatistikleri 2013 raporu verilerinden hareketle yazarlar tarafından hesaplanan Türkiye'de yolcu taşıma kapasitesi 2018 yılı için $380 \mathrm{Mkm}$ iken, yük taşıma kapasitesi 275 Mkm’dir [8].

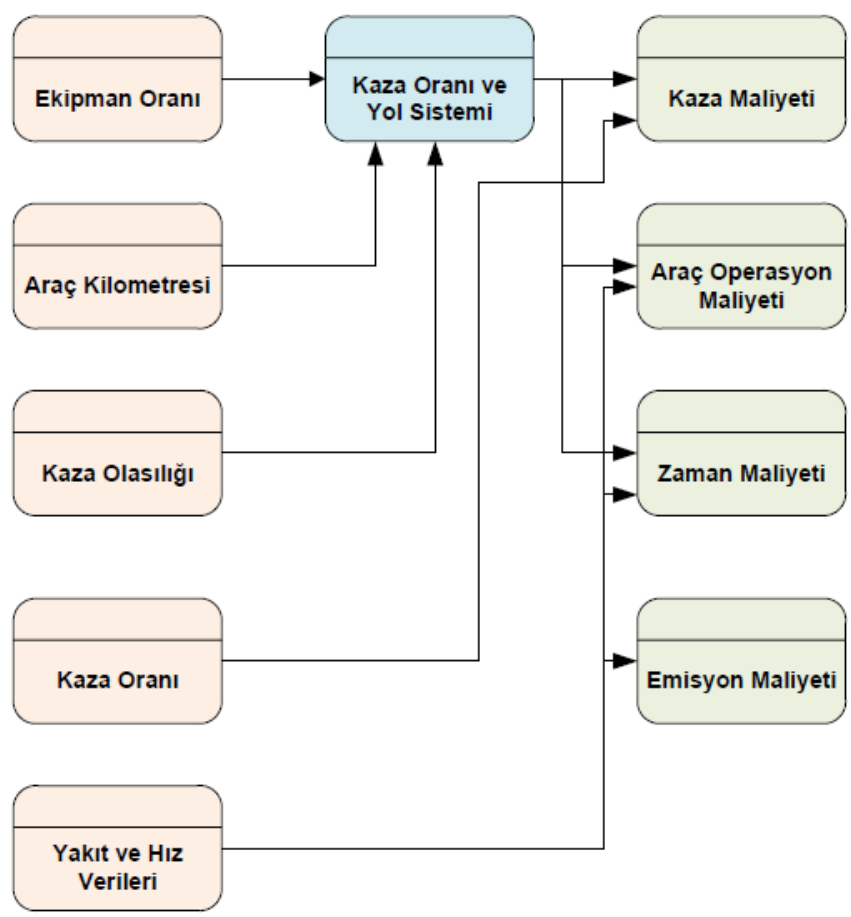

Şekil 4. Akıllı Araç Sistemleri Maliyet Modeli Yapısı

Araç Kazası Olasılı̆̆g: Seyir halindeki aracın kaza yapma olasılığı, kaza tipine ve sürücü reaksiyon hareketine bağlı bir fonksiyondur. Kaza tipleri, arkadan çarpma, yandan çarpma, sol şerit kazaları, kafa kafaya çarpma, kesişim bölgelerinde meydana gelen çarpışma, nesneye çarpma, yayaya çarpma ve diğer kazalar olarak 8 farklı yapıda incelenmektedir [9]. Sürücü reaksiyon süresi, ani durumlarda 0 ile 3 saniye arasında incelenmiştir [10]. Burada, 0.5 saniye en uygun değer, 2.5-3 saniye arası ise en kötü sürücü reaksiyon süresi olarak kabul edilmiştir. Bu reaksiyon süreleri, yukarıda ifade edilen kaza tipi ile ilişkilendirilip, çarpışma olasılığı olarak ifade edilmektedir.

Hız: Yol ve araç tipine de bağlı olarak sürüş istatistiklerinden elde edilen veriler 1şığında hız oranları belirlenir [11]. Burada yol tipleri otoyol, kentsel yol ve kırsal yol olarak ele alınmaktadır. Bu verilere bağlı 
olarak, tüm araçlar için kentsel yollardaki hız 23 ile 49 km/saat arasında; kırsal yollarda, ağır ticari araçlar dışında kalan araçlar için 39 ile $87 \mathrm{~km} / \mathrm{saat}$ arasında, ağır ticari araçlar için ise 40 ve $77 \mathrm{~km} / \mathrm{saat}$ arasında varsayılır. Otoyollarda ise, ağır ticari araçlar dışında kalan araçlar için hız 91 ile 109 km/saat arasında iken, ağır ticari araçlar için 76 ile $84 \mathrm{~km} / \mathrm{saat}$ arasındadır.

Yakıt: Yakıt girdisi bir ülkede trafikte seyreden araçlarca tüketilen yıllık yakıt miktarı olarak tanımlanır. Bu çalışmada MIT Enerji Çevre Raporu verilerinden yararlanarak bu değer Türkiye için 2018 yılında olmak üzere $23 * 10^{9}$ litre/yıl benzin ve $12 * 10^{9}$ litre/yıl dizel yakıt olarak hesaplanmıştır [14].

Kaza Ehemmiyet Katsayısı: Kazalar, kaza ehemmiyeti açısından ölümlü, ağır ve hafif yaralanmalı olarak 3 tipte incelenmektedir. Avrupa Birliği ülkelerinde ölümlü bir kazanın birim maliyeti $1516 \mathrm{M€}$ iken, ağır yaralanmalı bir kazanın birim maliyeti 0.2 M€'dur [1]. Ayrıca, hafif yaralanmalı bir kazanın maliyeti ise $22000 €$ 'dur. Türkiye için bu birim maliyetler TL/€ kuruna uyularak güncellenir. Bu verilerden ölümlü kazaları azaltmanın getirdiği maddi faydanın yaralanmalı bir kazaya oranla en az 7 kat daha fazla maddi getiriye sahip olduğu gözlemlenir.

Toplam Araç Kilometresi: Bu çalışmada, Karayolları Genel Müdürlüğü verilerinden hareketle Türkiye'deki otoyol oranı $\% 4$, kentsel yol oranı $\% 49$, kırsal yol oranı ise $\% 47$ olarak alınmıştır [12]. Örnek vermek gerekirse; kentsel yoldaki ağır yaralı kazalar ele alınırken, kentsel yol oranı olan \%49'un, Türkiye'de yıllık yapılan yolcu taşıma kilometresi olan $380 \mathrm{Mkm}$ ile, veya yıllık yapılan yük taşıma kilometresi olan 275 Mkm ile, veya yolcu ve yük taşıma toplam kilometresi olan $655 \mathrm{Mkm}$ ile çarpılıp; o yola ait taşıma kilometresinin bulunmasinı ifade eder.

Kaza Sayısı: Avrupa Birliğinde, yol altyapısı iyi ve kötü olmak üzere ülkeler iki bölümde incelenmektedir. Avrupa Birliği 2003 raporuna göre, yol yapısı iyi ülkelerde kaza oranları otoyolda 2 ile 4 arası, kentsel yolda 3 ile 5 arasındadır [15]. Yol yapısı kötü ülkelerde ise, bu oran otoyolda 9 ile 15, kentsel yolda 15 olarak alınır. Bu oranlar 1000 Mkm'deki kaza riskini ifade etmektedir.

Toplam Zaman Maliyeti: Bir ülkede yıllık bazda trafikte kaybedilen zaman olarak tanımlanan toplam zaman maliyeti (TZM), zaman birim maliyetinin (ZBM) o ülkedeki toplam araç kilometresinin (TAK) hıza (v) oranı ile çarpımı olarak ifade edilir.

$$
\mathrm{TZM}=\mathrm{ZBM} *(\mathrm{TAK} / \mathrm{v})
$$

ZBM, ülkelere göre oranları değişmekle birlikte, binek araçlar için 10 ile $15 € /$ saat arasında, ağır ticari kamyonlar için 15 ile $30 € /$ saat arasında ve otobüsler için 60 ile $90 € /$ saat arasında değiş̧en değerler almaktadır [16].

Araç Maliyeti: Araç maliyeti; araç operasyon maliyeti ve yakıt maliyeti olarak iki kısımdan oluşur. Operasyon maliyeti, ülkelere göre değişen sabit operasyon birim maliyetinin, toplam araç kilometresi ile çarpımı sonucu oluşur. Sabit araç operasyon maliyeti; binek araçlar için $9.16 € / 100 \mathrm{~km}$, kamyonlar için $14.19 € / 100 \mathrm{~km}$, yarı römork araçlar için $24.37 € / 100 \mathrm{~km}$ ve otobüsler için $45.90 € / 100 \mathrm{~km}$ 'dir [17]. Yakıt tüketimi ise aşağıda ifade edilmektedir [9].

$$
\mathrm{YTM}=[(\mathrm{YT} * \mathrm{YTS}) / \mathrm{YTF}]+[\mathrm{YT} * \mathrm{YTS} * \mathrm{YTBM}]
$$

Burada YTM yakıt tüketim maliyetini, YT ülkedeki yıllık araç yakıt tüketimini, YTS değeri 10 olan yakıt tüketim sabitini, YTF yakıt tüketim faktörünü, YTBM ise yakıt tüketim birim maliyetini ifade eder. YTBM ise yakıt tipine (benzin/dizel) göre değişkenlik gösteren; benzin için net hacimde $0.185 € /$ litre, dizel için net hacimde $0.189 € /$ litre olan birim maliyettir [13].

Emisyon Maliyeti: Emisyon maliyeti (EM); yakıt tüketimi (YT), emisyon faktörü (EF) ve emisyon birim maliyetine (EBM) bağlı bir fonksiyon olarak verilir:

$$
\mathrm{EM}=\mathrm{f}(\mathrm{YT}, \mathrm{EF}, \mathrm{EBM})
$$


Emisyon faktörü, Euro-1 ile Euro-6 arasında araç tipleri için her yıl güncellemeleri ile yayınlanan emisyon el kitaplarından tedarik edilir [18]. EBM değeri NOx gazı için ve $\mathrm{CO}_{2}$ gazı için tedarik edilmelidir. NOx gazı birim maliyeti Avrupa Komisyonu Extern-E programından tedarik edilir [19]. $\mathrm{CO}_{2}$ birim maliyeti ise $0.205 € / 1 \mathrm{~kg}-\mathrm{CO} 2$ olarak referans raporlardan veya ilgili kurumlardan tedarik edilebilmektedir [9].

Kaza Maliyeti: Araç kazası maliyeti (AKM), kaza birim maliyeti (KBM), kaza ehemmiyet katsayısı (KEK) ve yıllık olarak ülkede gerçekleşen kaza sayısına (KS) bağlı bir fonksiyondur.

$$
\mathrm{AKM}=\mathrm{f}(\mathrm{KBM}, \mathrm{KEK}, \mathrm{KS})
$$

Alt yapı sistem maliyeti (ASM) ise sistem maliyeti (SM), kurtarma servis sayısı (KSS) ve çalışan eğitim maliyetinin (ÇEM) bir fonksiyonudur.

$$
\mathrm{ASM}=\mathrm{f}(\mathrm{SM}, \mathrm{KSS}, \mathrm{ÇEM})
$$

Burada, ÇEM, yeni acil yardım servisleri çalışanı eğitim maliyeti, Avrupa Birliğinin seyahat ve eğitim harcamaları yönetmeliklerine bağlı kalınarak, yemek, otel, seyahat masrafları, yıllık eğitim sayısı ve toplam çalışan sayılarına bağlı bir fonksiyon olarak hesaplanır [20]. Sistem maliyeti SM yapısında var olan 8 alt grup Şekil-5'te ifade edilmektedir.

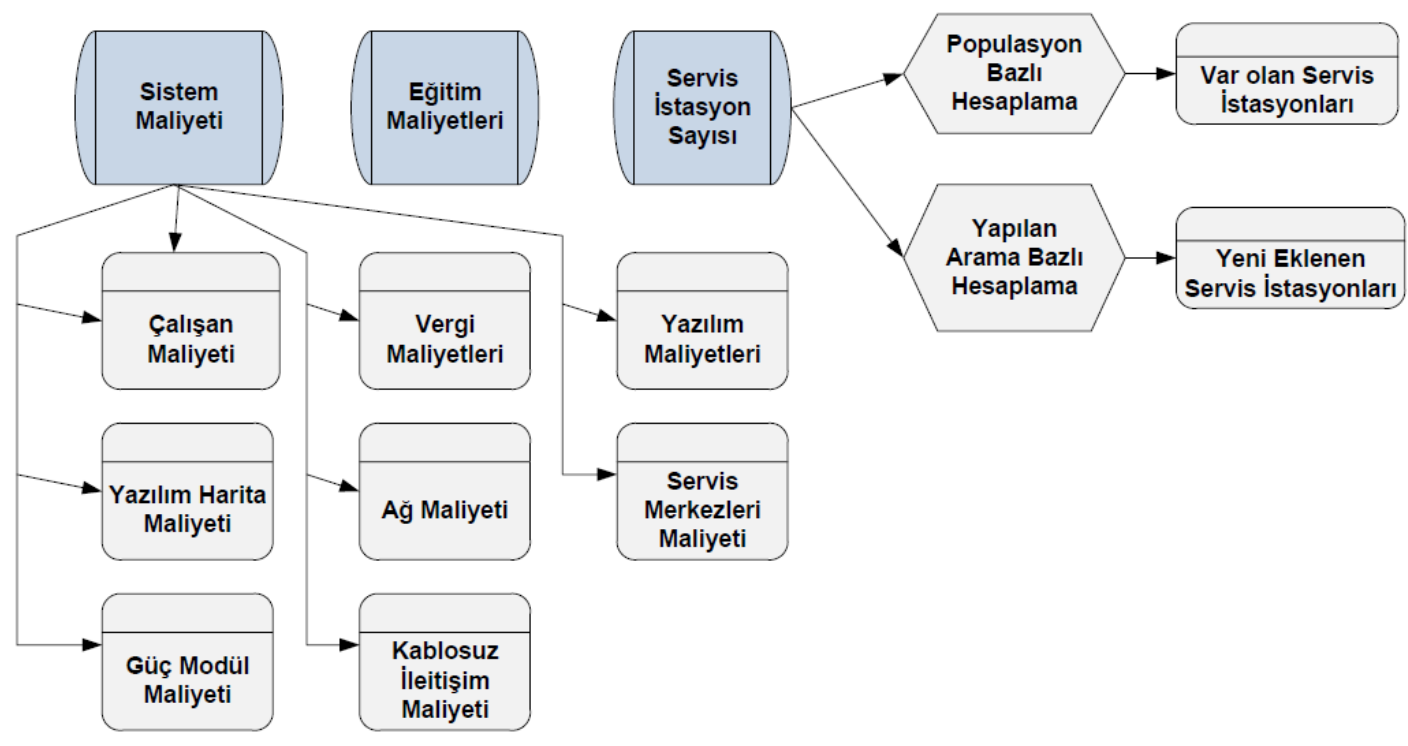

Şekil 5. Altyapı Sistemi Maliyet Birimleri

Çalışan maliyeti (ÇM) bir önceki bölümde açıklanan yeni kaza sayısının, çalışan kişi sayısına oranı ile bulunan kişi sayısının maliyetidir ve aşağıdaki gibi ifade edilebilir.

$$
\text { ÇM }=\left(\mathrm{KSSÇ}^{*} \mathrm{SÇÜ} * C ̧ S *(\mathrm{UÇG}+\mathrm{EÇG})\right)+\ddot{U} U ̈
$$

Bu formülde, KSSÇ kurtarma servisleri sayısında bulunan toplam çalışanı, SÇÜ saatlik çalışma ücretlerini, ÇS çalışma saatlerini, UÇG uygun çalışma günlerini, EÇG eğitimdeki çalışma günlerini ve ÜÜ üyelik ücretlerini temsil etmektedir.

Şekil-5'te yer alan Servis Merkezleri Maliyeti girdisi maliyetleri yıllık kaza sayısı ile oluşan arama süresini, çalışan sabit maaş ücretlerini, yeni açılan ofis varsa onun maliyetlerini içermektedir. Burada, bir acil çağrının bir dakikadaki ücreti $0.3 €$ ile $0.6 €$ arasında, yanlış aramalar için ücret ise $0.1 €$ ile $0.2 €$ arasında alınmıştır. 
A $\breve{g}$ Maliyeti girdisi ağ altyapısına ait maliyetleri, Yazılım ve Yazllım Harita maliyeti ise acil çağrı servis çalışanı bilgisayar yazılımı, harita programları ve bunların periyodik bakımlarını kapsayan maliyetleri ifade etmektedir. A $\breve{g}$ maliyeti ilk yardım servislerinin kablosuz iletişim donanımlarını, kablosuz servis ücretlerini, veri tabanı, numara tanımlama sistemi ve kablosuz iletişim testlerinin maliyetlerini içermektedir. Yine Şekil-5'te yer alan Güç Modülü girdisi ilk yardım servislerinin hiç sinyal kesintisi yaşamadan beslenmesini sağlayan modüllerinin maliyetleridir. Vergi girdisi maliyeti iş istasyonu (workstation) donanımları ve toplamda var olan iş istasyon sayısına bağlı olarak hesaplanan maliyet ile ylllık her bir doğru ve yanlış aramadaki vergi maliyetini içeren hesaplama birimidir.

Servis İstasyon Saylsı, 112 servisleri ve yeni açılacak acil çağrı servislerini ifade eder. 112 servisleri popülasyon bazlı olarak var olan mevcut servislerin sayısı ile, yeni eklenen acil çağrı servisleri ise yıllık yapılan acil arama ile ele alınmaktadır. Örneğin, küçük ölçekli bir acil çağrı istasyonunda 2 ile 4 tane, orta ölçekli acil çağrı istasyonunda 5 ile 20 tane ve büyük ölçekli acil çağrı istasyonunda 20 ile 50 tane arasında iş istasyonu bulunabilir [21] ve iş istasyonsuz servisler de altyapının uygunluğuna bağlı olarak oluşturulabilir.

\subsection{Akıllı Araç Sistemleri ve Alt Yapı Maliyet Modelleri}

$\mathrm{Bu}$ bölümde daha önceki kısımlarda verilen modeller farklı mimarilere uygulanmış ve en uygun mimari maliyet ve alt yapıya uygunluk kriterleri altında tespit edilmiştir. Bu hesaplamalar yapılırken bazı varsayımlarda bulunulmuştur. Bu varsayımlar sırasıyla şu şekildedir: Hesaplamalarda yakıt tipi dizel ve benzin olarak incelenmiş ve yakıt hacmi net hacim olarak ele alınmıştır. Emisyon değerleri EU-6 standartlarındaki değerler olarak seçilmiştir. Acil çağrıların konuşma süresi 1.5 dakika ile 2 dakika arasında, sürücü reaksiyonu ise 0 ile 3 saniye arasında seçilmiş ve çalışma saatleri 8 ile 12 saat arasında kabul edilmiştir. Yakıt tüketim sabitlerinin hesabında Lam formülü kullanılmıştır.[22] Araç içi acil çağrı ünitesi birim fiyatlarının $100 €$ ile $150 €$ arasında olduğu ve kendini 8 yıllık bir zaman zarfında \%3 iskonto ile amorti edeceği düşünülmüştür. Acil yardım servislerinin ise 20 yıl içinde $\% 3$ iskonto ile kendini amorti edecek şekilde planlandığı varsayılmıştır. Öte yandan hesaplamalarda, Avrupa Komisyonu seyahat harcamaları kuralları geçerli kabul edilmiş, üyelik ücretleri yine Avrupa Birliği parametreleri olarak ele alınmıştır. Akıllı araç teknolojileri donanım oranı ACEA raporlarından yararlanılarak hesaplanırken, popülasyon verileri Dünya Bankası popülasyon verilerinden elde edilmiştir. Yük ve yolcu taşıma kapasiteleri tüm araçlar için ele alınıp, özellikle binek araçlar için hesaplamalar yapılmıştır. Türkiye yol verileri iyi ve kötü yol şartları parametreleri için detaylandırılmış, tüm yol tipleri (otoyol, kırsal, kentsel) ve tüm kaza tipleri (ölümlü, ağır yaralı ve hafif yaralı) olarak ayrı ayrı incelenmiştir. Çalışmada ileriye yönelik olarak 2018 yılına ait tüzükler ve 2018 yılı parametreleri uygulanmıştır. Ayrıca, yapılan analizlerde Türkiye için şu durumlar alt grup olarak incelenmiştir:

(i) Kentsel yol'da hafif yaralanmalı kazalar,

(ii) Kırsal yol'da ağır yaralanmalı kazalar,

(iii) Otoyol'da ölümlü kazalar

Elde edilen sonuçlar Şekil-6'da tablo biçiminde yüksek fayda ve düşük maliyete göre soldan sağa doğru ifade edilmiştir. Kâr maliyet oranı ve net kâr yukarıda belirtilen 3 alt sistem için analiz edilmiştir. 


\begin{tabular}{|c|c|c|c|c|c|c|}
\hline \multirow[b]{2}{*}{ Veri ve Oranlar } & \multicolumn{2}{|c|}{ AZ FAYDA } & \multicolumn{2}{|c|}{ Mimari Ceş̧itleri } & \multicolumn{2}{|c|}{ YÜKSEK FAYDA. } \\
\hline & $\begin{array}{l}\text { MODEL-4 } \\
\text { Çeşit-6 }\end{array}$ & $\begin{array}{l}\text { MODEL-4 } \\
\text { Çeşit-4 }\end{array}$ & $\begin{array}{l}\text { MODEL-4 } \\
\text { Çeşit-5 }\end{array}$ & $\begin{array}{l}\text { MODEL-4 } \\
\text { Çeşit-3 }\end{array}$ & $\begin{array}{l}\text { MODEL-4 } \\
\text { Çeşit-2 }\end{array}$ & $\begin{array}{l}\text { MODEL-4 } \\
\text { Çeşit-1 }\end{array}$ \\
\hline $\begin{array}{c}\text { KMO-Kentsel } \\
\text { Yolda Hafif Yaralı } \\
\text { Kazalar } \\
\end{array}$ & 566,154 & 615,958 & 650,323 & 650,905 & 759,997 & 760,604 \\
\hline $\begin{array}{c}\text { KMO--Kırsal } \\
\text { Yolda Ağır Yaralı } \\
\text { Kazalar }\end{array}$ & 156,065 & 169,793 & 179,267 & 179,427 & 209,499 & 209,667 \\
\hline $\begin{array}{l}\text { KMO--Otoyolda } \\
\text { Ölümlü Kazalar }\end{array}$ & 3361 & 3657 & 3861 & 3864 & 4512 & 4515 \\
\hline \begin{tabular}{|c|} 
Net Kar-Kentsel \\
Yolda Hafif Yaralı \\
Kazalar
\end{tabular} & $4063379 \mathrm{~T} €$ & $4063961 \mathrm{~T} €$ & $4064310 \mathrm{~T} €$ & $4064315 \mathrm{~T} €$ & $4065213 \mathrm{~T} €$ & $4065217 \mathrm{~T} €$ \\
\hline $\begin{array}{c}\text { Net Kar--Kırsal } \\
\text { Yolda Ağır Yaralı } \\
\text { Kazalar }\end{array}$ & $1114 \mathrm{M€}$ & $1115.4 \mathrm{M} €$ & $1115.8 \mathrm{M} €$ & $1115.8 \mathrm{M} €$ & 1116.730 M€ & $1116.734 \mathrm{M} €$ \\
\hline $\begin{array}{l}\text { Net Kar--Otoyolda } \\
\text { Olümlü Kazalar }\end{array}$ & 24161.02 M€ & 24161.61 M€ & $24161.96 \mathrm{M} €$ & $24161.96 \mathrm{M} €$ & $24162.863 \mathrm{M} €$ & 24162.867 M€ \\
\hline $\begin{array}{l}\text { Toplam Acil } \\
\text { Servis Maliyeti }\end{array}$ & 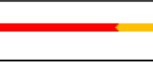 & 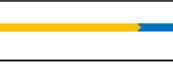 & $\longrightarrow$ Fayda & Kâr artışını göst & stermektedir & \\
\hline $\begin{array}{c}\text { (Araç Acil } \\
\text { Yardım+Diğer }\end{array}$ & $17675.57 \mathrm{M} €$ & $17675.01 \mathrm{M} €$ & $17674.67 \mathrm{M} €$ & 17674.66 M€ & $17673.79 \mathrm{M} €$ & $17673.78 \mathrm{M} €$ \\
\hline \begin{tabular}{|c} 
Halk \\
Konuları+Tüm \\
112 \\
Maliyetleri)Tüm \\
Yollar, Tüm Kaza \\
Tipleri \\
\end{tabular} & & & $\rightarrow$ Minim & $\begin{array}{l}\text { um Servis Maliye } \\
\text { Göstermekte }\end{array}$ & $\begin{array}{l}\text { etleri Düşüşü } \\
\text { edir }\end{array}$ & \\
\hline
\end{tabular}

Şekil 6. 2 Seviyeli Çă̆rı Merkezi Modeli Yeni Mimarisi Benzetim Sonuçları

Şekil-6'da KMO ve net kâr değerleri tüm senaryolar için Model-4 Çeşit-1'de en faydalı değere sahiptir. Sonrasında, Model-4 Çeşit-2'nin Türkiye için en iyi ikinci seçenek olduğu ve üçüncü alternatifin ise Model-4 Çeşit-3 olduğu belirlenmiştir. KMO, kentsel yollardaki hafif kazaları inceleyen durumda 550 ile 760 arasındaki değerler alırken, kırsal yollardaki ağır yaralı durum için 150 ile 210 arasında; otoyollardaki ölümlü kazalarda ise 3300 ile 4510 arasında bir orana sahiptir. KMO'nun oransal olarak otoyollardaki ölümlü kazalarda en yüksek değerlerde olma sebebi; kaza birim maliyetinin ölümlü bir kazada $1516 \mathrm{M€}$ iken, ağır yaralı bir kazada $0.2 \mathrm{M} €$ ve hafif yaralı kazada $22000 €$ olmasıdır. Net kâr, kentsel yol hafif yaralı kazalar durumu için $4 \mathrm{~B} €$ değerlerinde iken, kırsal alan ağır yaralı kazalarda $1.1 \mathrm{~B} €$ dolaylarında ve otoyollardaki ölümlü kazalarda ise $24 \mathrm{~B} €$ değerlerindedir. Öte yandan, toplam acil servis maliyeti yaklaşı $17 \mathrm{~B} €$ değerlerindedir. (Burada $\mathrm{T} €$ (yada $\mathrm{K} €$ ), $\mathrm{M} €$ ve $\mathrm{B} €$ kısaltmaları sirasıyla $10^{3}$, $10^{6}$ ve $10^{9}$ Avro'yu temsil etmektedir.)

$\mathrm{Bu}$ detaylı inceleme sonucunda Türkiye araç acil çağrı ünitesi regülasyonları sonrası yeni mimaride altyapısal olarak sıralaması, en iyiden en kötüye doğru (i) Model-4 Çeşit-1, (ii) Model-4 Çeşit-2, (iii) Model-4 Çeşit-3, (iv) Model-4 Çeşit-5, (v) Model-4 Çeşit-4, (vi) Model-4 Çeşit-6 olarak bulunmuştur. Türkiye'de bu alanda ilk kez yapılan bu çalışmada, yayının giriş kısmında tanımı ve yapısı verilen Model-4 Çeşit-1'in Türkiye için maliyet açısından en uygun mimari olduğu tespit edilmiştir.

\section{SONUÇ (CONCLUSION)}

Bu çalışmada yeni nesil akıllı araç sistemlerinin yapılanması konusu tanıtılmış ve HeERO-2 Proje Final Raporu-2'de [4] Türkiye'nin oluşturacağı yapı genel bir şekilde tanıtılmıştır. Araç içi acil çağrı ünitelerinin zorunlu hale gelmesiyle ortaya çıkabilecek yeni mimariler tartışılmış ve bunlar arasından en uygun mimari gerek maliyet gerekse altyapısal olarak Türkiye için ilk kez ele alınmıştır. Yazarlar tarafından önerilen HeERO-2 uyumlu en uygun mimari için Türk Patent Enstitüsüne TPE 2016/00021 patent no'su ile bir başvuru yapılmıştır. Yazarlar akıllı araç sistemlerinde araç içi modüllerin optimal konumuna dair çalışmalarına devam etmektedir. 


\section{KAYNAKLAR (REFERENCES)}

[1] The IRTAD road safety annual report 2015. http://www.oecd-ilibrary.org/ transport/road-safety-annualreport-2015_irtad-2015-en. Yayın tarihi Ekim 12, 2015. Erişim tarihi Şubat 28, 2017.

[2] T.C. Ulaştırma ve Denizcilik Bakanlığı Ulaştırma Kaza İstatistikleri 2013. http://www.ubak.gov.tr/BLSM_WIYS/KAIK/tr/Belgelik/20140312_103823_76347_1_76648.pdf.

Yayın tarihi Mart 12, 2014. Erişim tarihi Şubat 28, 2017.

[3] Official Journal of the European Union. Regulation (Eu) 2015/758 of the European Parliament and of the council. http://eur-lex.europa.eu/eli/reg/2015/758/oj. Yayın tarihi Nisan 29, 2015. Erişim tarihi Şubat 28, 2017.

[4] ERTICO, HeERO, Harmonised eCall European Pilot. D6.2 eCall deployment enablers and opportunities and challenges: Final Report. 2014.

[5] Antalya Valiliği, Turkish 112 single emergency call number project http://www.eena.org/ressource/static/files/112_in_turkey.pdf. Yayın tarihi Haziran 20, 2016. Erişim tarihi Şubat 28, 2017.

[6] European Committee for Standardization, Standard: CEN-EN-15722, Intelligent Transport Systems eSafety - eCall Minimum Set of Data, 2015.

[7] European Automobile Manufacturers Assosiation, ACEA, Consolidated Registrations - by country", http://www.acea.be/statistics/tag/category/by-country-registrations, Yayın tarihi Aralık, 2016. Erişim tarihi Mart 15, 2017.

[8] TOBB Türkiye Ulaştırma ve Lojistik Meclisi Sektör Raporu, TOBB Yayın Sıra No: 2015/260, 14 -16, 2014

[9] Abele J., Kerlen C., Krüger S., The Assessment of the Socio-economic Impact of the Introduction of Intelligent Safety Systems in Road Vehicles - Findings of the EU Funded Project SeiSS, Advanced Microsystems for Automotive Applications, Editörler: Valldorf J., Gessner W., Springer, Berlin, Almanya, 49 - 57, 2005.

[10] McLaughlin S.B., Analytic Assessment of Collision Avoidance Systems and Driver Dynamic Performance in Rear-End Crashes and Near-Crashes, Doktora Tezi, Virginia Polytechnic Institute and State University, A.B.D., 2007.

[11] Andre, M., Hammarstrom, U., Reynaud, I., Driving Statistics for the Assessment of Pollutant Emissions from Road Transport, INRETS Report LTE 9906, 170 - 172, Bron, France, 1999.

[12] UDH Bakanlığı, Karayolları Genel Müdürlüğü, kgm.gov.tr/Sayfalar/KGM/SiteTr/ Kurumsal/YolAgi.aspx,Yayın tarihi Ocak 25, 2015. Erişim tarihi Mart 15, 2017.

[13] Geels A., E-MERGE compiled evaluation results. E-MERGE Final report, deliverable 6.3. Cap Gemini Ernst \& Young, 2004

[14] Bodek, K., Heywood, J., Europe's evolving passenger vehicle fleet: Fuel use and GHG emission scenarios through 2035, Cambridge: Laboratory for the Energy and Environment, MIT, A.B.D. 29 31, 2008.

[15] Commission of the European Communities, Extended impact assessment of the proposal for a decision amending decision, The trans-European transport network, No: 1692/96/EC, Brüksel, Belçika, 2003.

[16] Planco Consulting GmbH, Numerische Aktualisierung interner und externer Beförderungskosten für die Bundesverkehrswegeplanung (BVWP) auf den Preisstand des Jahres 1998, Almanya Ulaştırma, İmar ve İskân Bakanlığı Kapanış Raporu, No: 537, 16 - 17, Berlin, Almanya, 2000. 
[17] FGSV, Empfehlungen für Wirtschaftlichkeitsuntersuchungen an Straßen: Forschungsgesellschaft für Straßen- und Verkehrswesen, Yol ve Ulaşım Araştırma Derneği Yayını, EWS-97, 12 - 13, Köln, Almanya, 1997.

[18] Continental Worldwide Emission Standards and Related Regulations March 2015 Passenger Cars, Light and Medium Duty Vehicles, http://www.continentalautomotive.com/www/download/automotive_de_en/general/contact_services/downloads/passenger_c ars/powertrain/common/p_emission_booklet_pdf_en.pdf

[19] Bickel P., Friedrich R., Externalities of Energy, Office for Official Publications of the European Communities, 253 - 259, Lüksemburg, 2005.

[20] European Commission Research Directorate General, Policy for Travel Expenses, https://ec.europa.eu/info/sites/info/files/rules_on_travel_expenses_for_applicants_0.pdf Yayın tarihi Aralık 07, 2016. Erişim tarihi Mart 16, 2017.

[21] Miller J., Thompson P., PSAP Merger Analyse for Wisconsin Agencies: Pierce and St.Croix Counties, PSC Alliance, Wisconsin, A.B.D., 30 - 35, 2014.

[22] Biggs D.C., Akçelik R.: 'Estimating effect of vehicle characteristics on fuel consumption, ASCE Journal of Transportation Engineering, 1987, Vol. 113, No: 1, pp.101-106 